\title{
As concepções teóricas de avaliação de documentos de arquivo na legislação brasileira
}

Maria Ivonete Gomes do Nascimento

ivonetenascimento40@gmail.com

Eliane Braga Oliveira

elianebo@unb.br

Universidade de Brasília, Faculdade de Ciência da Informação, Brasília, DF, Brasil

Resumo: Apresenta resultado de pesquisa sobre avaliação de documentos de arquivo na Administração Pública Federal brasileira, desenvolvida no curso de mestrado do Programa de Pós-Graduação em Ciência da Informação, da Faculdade de Ciência da Informação, da Universidade de Brasília. A avaliação de documentos de arquivo, uma das principais operações da gestão de documentos, visa a promoção da eficiência administrativa e a preservação da memória das organizações e da sociedade. A pesquisa tem como objetivo mapear a legislação brasileira referente à avaliação de documentos de arquivo e identificar as vertentes teóricas internacionais e nacionais que embasam essa legislação. Realizou-se uma pesquisa bibliográfica a respeito do tema em autores da Europa, América do Norte, América Latina e Brasil, e identificou-se a legislação brasileira referente ao assunto. Verificou-se que existe uma variedade de proposições referentes a avaliação de documentos de arquivos. Observou-se que a teoria do valor, apresentada como critério para a guarda ou a eliminação de documentos e proposta pelos autores norte-americanos Philip Brooks e Theodore Schellenberg, tem predominância conceitual na legislação brasileira.

Palavras-chave: administração pública federal; avaliação de documentos de arquivo; gestão de documentos; legislação brasileira.

The theoretical conclusions of assessment of archival records in Brazilian law

Abstract: This paper presents the results of a research on archival appraisal in Brazilian Federal Public Administration that was developed as part of the Master's Degree Program on Information Science in the Faculty of Information Science, at the University of Brasília. The archival appraisal, which is one of the main activities in records management, aims to promote administrative efficiency and preserve the memory of organizations and society. The purpose of this research is to map out the Brazilian legislation, which relates to archival appraisal and identify national and international theoretical influences that supported this legislation. It was conducted a bibliographical research regarding this subject on authors in Europe, North America, Latin America and Brazil, and the Brazilian legislation which refers to this topic was identified. It was established that there are a variety of conceptions related to archival appraisal. It was noted that the theory of records value which is presented as a criteria for keeping or eliminating documents by Philip Brooks and Theodore Schellenberg has conception predominance in Brazilian legislation.

Keywords: archival appraisal; Brazilian legislation; federal public administration; records management.

Las tesis teóricas de la evaluación de los registros de archivos en la legislación brasileña 
Resumen: Presenta los resultados de la investigación sobre valoración de documentos de archivo de la Administración Pública Federal brasileña. La investigación se desarrolló en el Programa de Postgrado de Maestría en Ciencias de la Información, de la Facultad de Ciencias de la Información, de la Universidad de Brasilia. La valoración, una de las principales operaciones de gestión de documentos, tiene como objetivo promover la eficiencia administrativa y la preservación de la memoria de las organizaciones y la sociedad. La investigación tuvo como objetivo analizar la legislación brasileña relativa a la valoración de los documentos e identificar fuentes teóricas internacionales y nacionales que apoyan dicha legislación. Se realizó una búsqueda en la literatura sobre el tema de autores procedentes de Europa, América del Norte, América Latina y Brasil, e identificamos la legislación brasileña sobre el tema. Se ha encontrado que hay varias propuestas relativas a la valoración de documentos. Se observó que la teoría del valor presentada como criterio para la custodia o la eliminación de documentos y propuesta por autores estadounidenses Philip Brooks y Theodore Schellenberg, tiene predominio conceptual en la legislación brasileña.

Palabras claves: administración pública federal; gestión de documentos; legislación brasileña; valoración de documentos. 


\section{Introdução}

A avaliação de documentos faz parte do novo paradigma na Arquivologia, que surgiu em meados do séc. XX como resposta ao crescimento exorbitante da produção documental ocorrida naquele período. O Dicionário Brasileiro de Terminologia Arquivística define a avaliação como um "processo de análise de documentos de arquivo, que estabelece os prazos de guarda e destinação, de acordo com os valores que Ihes são atribuídos" (ARQUIVO NACIONAL, 2005). É o mesmo conceito adotado pelo International Council on Archives (ICA), em sua base de dados Multilingual Archival Terminology, para a língua portuguesa.

Vários autores da área (COUTURE, 2003; COOK, 2006) advogam que a avaliação constitui um dos mais importantes fazeres arquivísticos. É considerada como uma das principais operações na gestão de documentos para a promoção da eficiência administrativa, como também é peça chave para a preservação da memória da instituição e da sociedade.

A avaliação está prevista na legislação de arquivo brasileira, a partir da Lei no $8.159 / 1991$, como uma das operações técnicas procedimentais da gestão de documentos. Na regulamentação da referida lei, consta a previsão de criação da Comissão Permanente de Avaliação de Documentos (CPAD) em cada órgão da Administração Pública Federal.

O Conselho Nacional de Arquivo (CONARQ) editou diversas resoluções orientadoras que tratam da avaliação. Da mesma forma, o Arquivo Nacional (AN) normatizou essa atividade por meio de instruções normativas e manuais técnicos.

A temática da preservação e eliminação dos documentos já era uma preocupação desde o Manual de Arranjo e Descrição de Arquivos produzido pela Associação dos Arquivistas Holandeses (1898), embora essa obra não apresente nenhuma solução para o problema. Com a evolução do pensamento arquivístico identifica-se uma variedade de proposições para a avaliação de documentos de arquivo, de forma que o debate permanece em pauta.

Este trabalho faz parte de pesquisa de mestrado sobre avaliação de documento de arquivo na Administração Pública Federal brasileira (APF), desenvolvida no âmbito do Programa de Pós-Graduação em Ciência da Informação da Faculdade de Ciência da Informação, da Universidade de Brasília.

Identifica-se na literatura da área que a avaliação de documentos é preocupação de vários países. Este trabalho dialogará com alguns autores estudiosos do tema.

\section{As Concepções Teóricas da Avaliação de Documentos de Arquivo}

Costumamos dizer que os arquivos são tão antigos quanto a escrita, assim como as pessoas que cuidavam dos documentos. A avaliação, no entanto, só foi compreendida como 
uma prática arquivística em meados do século $X X$, quando passou a ser aceita como intervenção necessária para controlar o crescimento exponencial do volume da informação registrada. Esse crescimento foi ocasionado por vários novos fatores administrativos, políticos, econômicos, tecnológicos e de comunicação. Ou seja, as mudanças na sociedade e seus reflexos foram sentidos diretamente nos arquivos. Dessa forma, havia pressão por respostas para as novas demandas - não somente a preservação dos documentos do passado, mas também o destino dos registros do presente que cresciam exponencialmente.

Os autores do Manual de Arranjo e Descrição de Arquivos da Associação dos Arquivistas Holandeses, Muller, Feith e Fruin chamam a atenção para o fato de que, desde 1813 , os documentos administrativos foram se acumulando em nível alarmante, correndo perigo de serem destruídos sem distinção ou discriminação por questão de economia ou de espaço. Na opinião de Jenkinson (1922, p.137), o debate a respeito do descarte de documentos se apresentou, inicialmente, como uma necessidade da modernidade. Antes disso, não havia discussão sobre a preservação dos documentos motivada pela falta de espaço nos arquivos.

Em meados do séc. XX, a seleção e a eliminação documental passaram a ganhar uma relevância ainda maior. Segundo Philip Brooks (1940), o trabalho de selecionar foi profundamente afetado pela maior quantidade de registros, mas também devido à ampliação de novos tipos de registros decorrentes da intensa atividade do negócio público.

Brooks (1940) propõe que sejam promovidos métodos inteligentes de seleção dos registros para a sua preservação. Esses métodos devem levar em conta os valores dos documentos em relação à instituição produtora, as políticas e os regulamentos administrativos que regem esse produtor, a história administrativa, bem como aqueles que envolvem direitos. Os que não contêm valor suficiente, seja um valor legal, administrativo ou de interesse histórico para a pesquisa, devem ser eliminados. Com essa proposição, o autor inaugura a atribuição de valores documentais admitidos como critério para a guarda ou eliminação de documentos (KOLSRUD, 1992, p. 28; SILVA et al., 1999, p. 131).

Schellenberg, em 1956, propõe que a avaliação dos documentos públicos modernos seja baseada em valores primários e secundários. Essa teoria consiste em preservar pouca documentação com o máximo de informação possível. A seleção deve ser compartilhada por arquivista e gestores de documentos para conservar o documento em caráter permanente ou eliminá-lo com segurança.

O valor primário, é o valor que o documento apresenta para os produtores. Parte do entendimento de que os documentos são criados para cumprir os objetivos de determinado 
órgão, sejam eles administrativos, fiscais, legais ou executivos. O valor secundário foi pensado como forma de garantir a preservação de informações relevantes para a produção do conhecimento e para a sociedade em geral. Nesse sentido, deveriam ser preservados documentos que comprovam a existência da organização, bem como seu funcionamento valor probatório -, e a informação sobre pessoas, entidades, coisas, problemas, condições, na relação institucional do órgão - valor informativo (SCHELLENBERG, 2002, p. 218). Em seu estudo sobre avaliação de documentos, Schellenberg registrou várias observações, tais como:

1. Não se pode reduzir a padrões exatos as considerações a serem observadas na determinação dos valores dos documentos. [...] Os padrões não devem ser encarados como absolutos ou finais. $\mathrm{Na}$ melhor das hipóteses, servirão tão-somente como guias para orientar o arquivista através dos traiçoeiros caminhos da avaliação.

2. Como os padrões de avaliação não podem ser exatos ou precisos, não precisam ser aplicados com absoluta consistência. Os arquivistas podem fazer uso de diferentes critérios de avaliação de documentos de diferentes períodos, pois o que tem valor para uma época passada pode ser insignificante para o presente. [...]

3. Uma vez que os padrões de avaliação não podem ser absolutos ou finais, devem ser aplicados com moderação e bom-senso. $O$ arquivista não deve conservar demais, nem de menos. [...]

4. A avaliação de documentos não deve se basear em instituição ou em suposições arbitrárias de valor. Deve ser, ao contrário, baseada na análise total da documentação relativa ao assunto a que se referem os documentos em questão. [...]

5. Se a sua análise não fornece a informação necessária à avaliação dos documentos, o arquivista deve procurar o auxílio de especialistas. [...]

6. Antes de buscar a ajuda de especialista o arquivista deve fazer o trabalho básico de análise, preliminar à avaliação de documentos. [...]

7. Ao procurar determinar o interesse dos especialistas por determinar grupos de documentos, o arquivista deve exercer o papel de moderador. [...] (SCHELLENBERG, 1956, 2002, p. 226)

Essas ideias trouxeram um novo enfoque, tanto para os arquivos, como para os arquivistas, que passaram a exercer um "papel de moderador" na tomada de decisão em relação à preservação e à eliminação dos documentos. Elas diferem da proposta de Jenkinson (1922), que defendia a não interferência do arquivista nesse processo, considerando que a tarefa de destruição dos registros cabia à própria administração.

Terry Cook, arquivista canadense, propôs outra abordagem da avaliação arquivística, quando iniciou os estudos desenvolvidos entre 1989 e 1990. Na ocasião, Cook escreveu o estudo do Programa de Gestão de Documentos e Arquivos (RAMP), do Programa Geral de 
Informação e UNISIST, da UNESCO, publicado em 1991. A partir desse estudo, Cook desenvolveu a macroappraisal, juntamente com outros colegas, no Arquivo Nacional do Canadá. Cook foi o diretor responsável pelo programa de implantação da macroavaliação de 1993 a 1998, no Arquivo Nacional do Canadá.

A macro avaliação propõe que os arquivos reflitam a sociedade que os gerou de forma holística, inclusiva, passando de um discurso focado no Estado para um discurso com foco na sociedade (COOK, 1996). Dessa forma, estabelece um olhar mais amplo sobre os documentos revelados pelas funções, programas, atividades e atuações dos produtores dos documentos. Isso envolve uma extensa pesquisa arquivística da funcionalidade institucional, da estrutura organizacional, da cultura do lugar de trabalho, dos sistemas de registros, do fluxo de trabalho informacional, da mídia e das tecnologias. (COOK, 2006). Portanto, esse contexto de produção dos documentos, dos objetivos para os quais foram criados, torna-se o centro das atividades do arquivista.

Terry Eastwood (2003), professor da University of British Columbia, no Canadá, levanta a suposição de que a avaliação tenha um objetivo subjacente e que esse objetivo depende do modelo de sociedade em que a avaliação é realizada. Para ele, em sociedades plurais também deve ocorrer pluralidade nos sistemas de arquivos.

Rousseau e Couture (1998), arquivistas canadenses, propõem a arquivística integrada como forma de assegurar uma política completa da organização dos arquivos, permitindo um rápido acesso às informações por meio de procedimentos integrados de classificação, avaliação e descrição. A avaliação é proposta como uma das funções ${ }^{1}$ nos arquivos correntes e intermediários.

Couture (2003) chama a atenção para o trabalho de determinação dos valores nos documentos, no qual o arquivista ao desenvolver a avaliação deve atentar para os cinco princípios básicos aplicáveis a todos os contextos:

- de que los archivos den testimonio del conjunto de actividades de la sociedade;

- de la objectividad y la contemporaneidad del critério que adopta;

- de respetar los nexos de unión entre la valoración y las demás intervenciones archivísticas;

- de que, em su intervención, exista equilíbrio entre los fines administrativos y los fines patrimoniales;

- de que exista equilíbrio entre las consideraciones relativas al contexto de creación de los documentos y las relativas a su uso. (COUTURE, 2003, p. 31).

1 As funções arquivísticas propostas são: criação, avaliação, aquisição, conservação, classificação, descrição e difusão dos arquivos. (ROUSSEAU; COUTURE, 1998, p. 265) 
Luciana Duranti (1994, p. 329), pesquisadora da Universidade de British Columbia, no Canadá e autora de vários estudos arquivísticos, ressalta que a atribuição de valor aos documentos, não ocorreu precedido da exploração do conceito de avaliação, mas somente a partir de reiterada repetição da necessária centralidade do trabalho arquivístico, e com isso procura fazer a sua legitimação. Essa autora afirma que a atribuição de valor aos documentos conflita-se com as características de naturalidade, inter-relação, imparcialidade e autenticidade dos documentos de arquivos.

Os estudiosos portugueses Ribeiro e Silva $(2004,2009)$ desenvolvem outra proposta da avaliação de documentos. Propõem o uso da informação por meio do Método Quadripolar como dinâmica de investigação qualitativa, em que a avaliação é vista como uma das operações do polo técnico desse método, ajustada às Ciências Sociais e Ciência da Informação. Os autores identificam três tipos de indicadores para a operacionalização da avaliação, são eles:

- A pertinência, que significa literalmente pertença à acção de alguém ou entidade, pode ser mensurável, em termos informacionais, através do trinómio OBJECTIVOS essenciais (razão de ser) + ESTRUTURA ORGÂNICA E COMPETÊNCIAS/FUNÇÕES + MEMÓRIA, numa gradação de três níveis $(A, B, C)$, correspondentes a uma relação directa, indirecta ou periférica, dos atos informacionais com o trinómio enunciado;

- A densidade, que significa à letra qualidade daquilo é denso, espesso, compacto, implica em termos informacionais, saber se um acto ou documento é primário/original, com/sem duplicação/cópia exacta, ou se é secundário (resumo ou síntese, parcela e acumulação de documentos primários/originais), com/sem duplicação/cópia;

- A frequência, que significa repetição amiudada de actos ou sucessos é entendida, aqui, como quantificação da periodicidade de uso/acesso à informação, quer na fase de produção/recepção (fase genésica ou decisória, chamada também corrente ou administrativa), quer na fase imediatamente posterior (fase estável, pós-genésica e pós decisória, que é perene e definitiva, assim como progressivamente mais aberta a um acesso externo ao sistema arquivo), podendo os resultados a obter em ambas as fases esclarecer-nos cabalmente sobre se há ou não um "uso intermédio" (muito discutível) e ainda se é verdade ou não que a Administração perde totalmente a necessidade de acesso a informação com mais de 40 anos de idade.(RIBEIRO e SILVA, 2004, p. 24)

Manuel Vázquez Murillo (2006, p. 35), arquivista argentino, afirma que entre a conservação e a eliminação total dos documentos está a seleção documental, que requer a apreciação dos valores dos documentos. Segundo o autor, o documento de arquivo nasce vinculado a uma tramitação. A vigência do documento está vinculada a sua força de obrigar, testemunhar ou provar. Portanto, nada vigente deve ser eliminado. O prazo entre o fim da 
vigência e a destinação final -- eliminação ou recolhimento ao arquivo permanente - é o chamado prazo precaucional. Durante esse período, o documento é preservado com objetivo de responder a obrigações administrativas.

Na opinião de Jardim (1995, p. 8), a avaliação é a função arquivística que mais sofre interferência intelectual do arquivista. O autor levanta a preocupação de que a justificativa da avaliação tende a privilegiar a memória como construção técnica do arquivista, por isso defende a revisão teórica e metodológica desse fazer, com o olhar voltado para o conceito de memória com privilégio dos aspectos da construção social em vez de "dado arqueologizável". Para esse autor, a avaliação consiste em recurso eficaz para a escolha dos documentos passíveis de integrar o patrimônio documental de uma sociedade e representar a memória de um grupo.

Santos (2005) ressalta que a avaliação dos documentos digitais deve considerar dois aspectos: a análise de conteúdo ou arquivística, que verifica a parte jurídica administrativa, a de procedimento, a de proveniência e a de documento; e a análise técnica em que se verificam os aspectos da tecnologia. Santos entende que não se deve transferir o mesmo processo de avaliação dos documentos tradicionais para os digitais, uma vez que esses registros exigem critérios específicos.

Norma Catalina Fenoglio (2012), ${ }^{2}$ destaca que a importância da avaliação reside na irreversibilidade da decisão tomada e no que isso pode comprometer o futuro das investigações históricas vindouras. Ressalta, ainda, que não existe em nível internacional, acordos totais acerca dos critérios a serem adotados na avaliação de documentos, em razão das diferenças das legislações, das normas técnicas, da tradição e das práticas arquivísticas.

Fica perceptível por esse estudo, que ocorre uma variedade de proposições em relação à avaliação de documentos de arquivo. $O$ que remete para esse debate, a preocupação em relação à subjetividade dessa avaliação, na escolha de quais documentos farão parte do patrimônio documental e a definição daqueles que serão eliminados e esquecidos para comporem a memória da sociedade.

\footnotetext{
${ }^{2}$ Responsável pelo Proyecto Evaluación de Documentos en Iberoamérica, desenvolvido com o apoio do ICA, com a participação de profissionais de oito países (Argentina, Peru, Costa Rica, México, Brasil, Colômbia, Espanha e Uruguai).
} 


\section{A Legislação Brasileira Sobre Avaliação de Documentos de Arquivo na Administração}

Pública Federal

A Norma Brasileira NBR 9578/1986, da Associação Brasileira de Normas Técnicas (ABNT) que define os termos usados nos arquivos, conceitua a avaliação como "processo de análise da documentação de arquivos, visando estabelecer a sua destinação, de acordo com seus valores probatórios e informativos." (ABNT, 1986). A mesma norma estabelece, como conceito de eliminação, a exclusão de documentos julgados sem valor para a guarda permanente e tabela de temporalidade como o instrumento de destinação dos documentos, com prazos de guarda nos arquivos corrente e intermediário.

A NBR 10519/1988, que trata dos critérios de avaliação de documentos de arquivo estabelece orientações para a seleção de documentos e orienta que para fazer avaliação, é desejável que os documentos estejam classificados. Acrescenta que o trabalho de análise e seleção deverá ser realizado no arquivo corrente. Determina que o valor primário se encontra no documento que tem valor administrativo para a instituição, valor fiscal, valor jurídico ou legal. Aquele de valor secundário é o que atende ao interesse dos usuários, principalmente pesquisadores.

A normatização dos documentos públicos e sua organização também estão explicitadas na Constituição Federal (CF) brasileira de 1988, conforme Quadro 1.

Quadro 1: dispositivos constitucionais na CF de 1988 relacionados com a Arquivologia

\begin{tabular}{|l|l|}
\hline \multicolumn{1}{|c|}{ Dispositivos } & \multicolumn{1}{c|}{ Conteúdo } \\
art. 5o, XXXIII & $\begin{array}{l}\text { Todos têm direito a receber dos órgãos públicos informações de seu interesse } \\
\text { particular, ou de interesse coletivo ou geral, que serão prestados no prazo da } \\
\text { lei, sob pena de responsabilidade, ressalvadas aquelas cujo sigilo seja } \\
\text { imprescindível à segurança da sociedade e do Estado. }\end{array}$ \\
\hline art. 23, III & $\begin{array}{l}\text { É de competência comum da União, dos Estados, do Distrito Federal e dos } \\
\text { Municípios: } \\
\text { (...) } \\
\text { III - proteger os documentos de valor histórico, artístico e cultural, os } \\
\text { monumentos, as paisagens naturais notáveis e os sítios arqueológicos. }\end{array}$ \\
\hline art. 216 & $\begin{array}{l}\text { Constituem patrimônio cultural brasileiro os bens de natureza material e } \\
\text { imaterial, tomados individualmente ou em conjunto, portadores de } \\
\text { referência à identidade, à ação, à memória dos diferentes grupos formadores } \\
\text { da sociedade brasileira, nos quais se incluem: } \\
\text { (...) } \\
\S 2 \text { co Cabem à administração pública, na forma da lei, a gestão da } \\
\text { documentação governamental e as providências para franquear sua consulta } \\
\text { a quantos dela necessitem. }\end{array}$ \\
\hline
\end{tabular}

Fonte: elaboração própria com base na Constituição Federal do Brasil de 1988. 
A lei no 8.159 , de 8 de janeiro de 1991, que trata da política nacional de arquivos públicos e privados - conhecida como a Lei de Arquivos brasileira - em consonância com a Carta Magna, reconhece a gestão documental e a proteção aos documentos de arquivo como dever do poder público. E prevê a avaliação de documentos, como parte da gestão de documentos. Está assim determinado no art.3을

Considera-se gestão de documentos o conjunto de procedimentos e operações técnicas referentes à sua produção, tramitação, uso, avaliação e arquivamento em fase corrente e intermediária, visando a sua eliminação ou recolhimento para a guarda permanente. (BRASIL, 1991)

Na regulamentação da Lei de Arquivos, o Decreto n.․ 4.073/2002, ao tratar da gestão de documentos da Administração Pública Federal, prevê que cada órgão deverá constituir Comissão Permanente de Avaliação de Documentos (CPAD), com o propósito de orientar e realizar análise, avaliação e seleção dos documentos, para definição daqueles de guarda permanente e a eliminação dos considerados sem valor.

O Conselho Nacional de Arquivo normatizou o processo de avaliação por meio de várias resoluções, tais como a Resolução de n. 2, de 1995. Após isso, o Arquivo Nacional instituiu a Instrução Normativa n.o 1, de 1997, que estabelece os procedimentos para a entrada de acervos de arquivos no Arquivo Nacional. Nesses procedimentos consta a previsão de que os acervos, ao serem transferidos ou recolhidos para essa instituição, deverão também estar avaliados.

Os prazos de guarda e destinação dos documentos relativos as atividades-meio estão definidas na Tabela de Temporalidade e Destinação conforme a Resolução no 14, de 2001, do CONARQ. Consta também a previsão de que a eliminação de documentos produzidos por instituições públicas e de caráter público só poderá ser realizada após autorização da instituição de arquivo pública, em sua respectiva esfera de competência.

Essa eliminação de documentos nos órgãos públicos só poderá ocorrer após a conclusão do processo de avaliação, implementado por essa comissão de avaliação de documentos. Deverão ser observados os procedimentos de publicação de editais, assim como da listagem e do termo de eliminação previstos na Resolução n.o 5, de 1996 e na Resolução n.으 7, de 1997 do referido Conselho.

A Resolução $\mathrm{n}$. o 6, de 1997 determina que as atividades de avaliação serão reservadas para execução direta pelos órgão e entidades do Poder Público, por considerá-las atividades 
essenciais da gestão de documentos, de responsabilidade de Comissão Permanente de Avaliação de Documento.

O Decreto n. 4.915 de 2003 cria o Sistema de Gestão de Documentos de Arquivo (SIGA), com a finalidade, entre outras, de racionalização da produção da documentação de arquivo na esfera pública. O Decreto designa o Arquivo Nacional como órgão central do Sistema e atribui aos órgãos setoriais a competência de implementar e acompanhar a avaliação de documentos. Além de coordenar a aplicação da Tabela de Temporalidade e Destinação de Documentos da área meio, os órgãos setoriais deverão também elaborar, por meio das CPAD, a Tabela de Temporalidade e Destinação relativa aos documentos das atividades-fim.

Na gestão dos documentos digitais, os órgãos ou entidades deverão adotar os mesmos procedimentos e critérios previstos para a avaliação e a destinação documental, na legislação em vigor. De acordo com a Resolução n. 20, de 2004, a eliminação desses documentos poderá ocorrer, caso esteja prevista na tabela de temporalidade dos órgãos.

Da mesma forma que os documentos analógicos, os documentos arquivísticos digitais, ao serem transferidos e recolhidos para instituição pública, deverão ser previamente identificados, classificados, avaliados e destinados, na forma determinada pela Resolução no 24, de 3 de 2006.

O e-ARQ Brasil propõe a adoção de modelo de requisito para Sistemas Informatizados de Gestão Arquivística de Documentos, de acordo com a Resolução n. 25, de 2007, por todos os órgãos e entidades do Sistema Nacional de Arquivos. Esse e-ARQ Brasil tem por objetivo orientar e implantar a gestão de documentos com o fornecimento de especificações técnicas e funcional, para os sistemas informatizados. Nele, a avaliação é definida como um processo de análise dos documentos, com objetivo de estabelecimento dos prazos de guarda e destinação, conforme os valores primários e secundários. A aplicação dos critérios da avaliação baseia-se na teoria das três idades e recomenda que ela seja iniciada no arquivo corrente, de forma a identificar os documentos de valor eventual, os de valor probatório e os de valor informativo. Define que no Sistema Informatizado de Gestão Arquivística de Documentos, a temporalidade e a destinação devem ser previstas na captura e no registro do documento.

A Resolução n. 36 , de 2012, que trata sobre a adoção de diretrizes para a gestão de documentos do correio eletrônico corporativo dos órgãos e entidades públicas, define que a destinação desses documentos deverá estar prevista na tabela de temporalidade e destinação em conformidade com a Resolução n.ำ14, de 2001. 


\section{Considerações Finais}

Da leitura dos autores apresentados podemos inferir que a temática da preservação e eliminação de documentos já era uma preocupação desde os autores do Manual de Arranjo e Descrição de Arquivos da Associação dos Arquivistas Holandeses, no entanto essa obra não formulou nenhuma solução para o problema. A eliminação dos documentos de arquivo, até meados do século XX, ocorria sem objetivos e critérios claros.

Ficou evidenciado que existe na literatura internacional de arquivo uma variedade de proposições para a avaliação de documento. Alguns autores partem do pressuposto da impossibilidade de guardar toda a produção documental contemporânea, razão pela qual desenvolvem propostas para a definição do que julgam ser importante para guardar para a posteridade como memória da sociedade e quais documentos devem ser suprimidos. Por outro lado, alguns estudiosos advogam a não eliminação de documentos, apesar de reconhecerem sua necessidade.

A Lei no 8.159/1991, marco legal dos arquivos em nosso país, estabelece que a avaliação de arquivo faz parte da gestão de documentos. Também prevê que devem ser definitivamente preservados os documentos considerados permanentes, que contenham valor histórico, probatório e/ou informativo. Essa diretiva está em comum acordo com a proposta de valor de Philip Brooks e de Teodore Schellenberg.

A Instrução Normativa AN/№1 de 1997, do Arquivo Nacional estabelece que a avaliação e seleção dos documentos precisa ser desenvolvida por Comissão Permanente de Avaliação de Documentos (CPAD). Essa proposta de comissão está ancorada na proposta de Schellenberg de que os documentos sejam examinados por vários especialistas da instituição, para determinar quais aqueles que contém informações consideradas relevantes a respeito de vários assuntos, sendo, o arquivista o moderador desse processo.

O Decreto no 4.073/2002, que regulamenta a Lei no 8.159/1991, reafirma e detalha a Instrução Normativa n.1/1997, do Arquivo Nacional, ao estabelecer que a análise, a avaliação e a seleção dos documentos produzidos e acumulados pelos órgãos produtores dos arquivos serão de responsabilidade das CPAD, reafirmando a influência do pensamento de Brooks e Schellenberg na legislação brasileira.

O Decreto no 4.915/2003 que cria o Sistema de Gestão de Documentos de Arquivo SIGA atribui competência às CPAD dos órgãos setoriais a elaboração da tabela de temporalidade e destinação de documentos de arquivo, relativos às atividades-fim. Essas proposições têm inspiração nas propostas de Brooks e Schellenberg. 
A Resolução n.o 2/1995, do Conselho Nacional de Arquivo, adota medidas para a transferência ou recolhimento dos documentos às instituições públicas de arquivo, condicionando-as à prévia avaliação dos acervos documentais. Esclarece que a transferência é considerada a passagem dos documentos do arquivo corrente para o arquivo intermediário e o recolhimento consiste na entrada dos documentos ao arquivo permanente. Essa proposição, claramente, se respalda no ciclo de vida dos documentos, conforme indicado por Schellenberg.

As Resoluções n. 5/1996, a n. 6/1997 e a n.ㅇ 7/1997 são de caráter meramente administrativo. Elas visam normatizar procedimentos em relação à eliminação de documentos e o processo de avaliação, sem, contudo, recorrer aos princípios teóricos da avaliação de documentos.

A Resolução no 14/2001, que institui o Código de Classificação de Documentos de Arquivo e a Tabela Básica de Temporalidade e Destinação de Documentos foram desenvolvidos com base nas funções e atividades dos órgãos públicos. Esses instrumentos são de uso obrigatório nas atividades de avaliação e destinação dos documentos da APF. Sugere que os conjuntos documentais produzidos e recebidos pela organização sejam tratados de forma integrada, no que diz respeito à classificação e à avaliação. Isso sugere, apesar de não explicitar, uma influência da arquivística integrada proposta pelos canadenses Jean-Yves Rousseau e Carol Couture. Cabe ressaltar que ainda não se trata da integração das três idades documentais, mas é uma possibilidade.

Em relação aos prazos de guarda dos documentos previstos na tabela como resultado da avaliação, a Resolução 14 adota o prazo de precaução, em razão da necessidade das práticas administrativas, o que nos remete à proposta do arquivista argentino Manuel Vázquez.

As Resoluções n.o 20/2004, a n.o 25/2007 e a n.o 36/2012 que tratam de procedimentos a serem adotados em relação aos documentos digitais, preveem a avaliação conforme a Lei no 8.159/91 e as Resoluções n ㄴ, no 7 e no 14, o que indica que a avaliação desses documentos é, da mesma forma, baseada na atribuição de valor, conforme a proposta de Brooks e de Schellenberg.

Constata-se que a legislação brasileira sobre avaliação de documentos de arquivo adota os conceitos de ciclo vital, dos valores primários e secundários na definição do prazo de guarda e na destinação dos documentos. Observa-se também a influência pontual de Manuel Vázquez, na utilização do prazo precaucional. É perceptível uma concepção de gestão de arquivos que pressupõe a integração das fases corrente, intermediária e permanente, conforme proposta dos autores Jean-Yves Rousseau e Carol Couture. 
Conclui-se, portanto, que apesar da presença pontual de outros autores, a teoria do valor apresentado como critério para a guarda ou a eliminação dos documentos iniciada por Brooks e aprofundada e disseminada por Schellenberg, é a base teórica sob a qual se sustenta a legislação brasileira.

\section{Referências}

ARQUIVO NACIONAL. Dicionário brasileiro de terminologia arquivística. Rio de Janeiro: Arquivo Nacional, 2005.

ARQUIVO NACIONAL. Instrução Normativa AN no 1, de 18 de abril de 1997. Estabelece os procedimentos para entrada de acervos arquivísticos no Arquivo Nacional. Diário Oficial da República Federativa do Brasil. Brasília: 1997.

ASSOCIAÇÃO BRASILEIRA DE NORMAS TÉCNICAS. NBR 9578: Arquivo: terminologia. Rio de Janeiro: ABNT, 1986.

ASSOCIAÇÃO BRASILEIRA DE NORMAS TÉCNICAS. NBR 10519: Critérios para avaliação de documentos de arquivo: procedimentos. Rio de Janeiro: ABNT, 1988.

ASSOCIAÇÃO DOS ARQUIVISTAS HOLANDESES. Manual de arranjo e descrição de arquivos. 2a ed. Rio de Janeiro: Arquivo Nacional, 1973.

BRASIL. Constituição da República Federativa do Brasil. Diário Oficial da República Federativa do Brasil. Brasília: 1988.

BRASIL. Lei no 8.159, de 8 de janeiro de 1991. Dispõe sobre a política nacional de arquivos públicos e privados e dá outras providências. Diário Oficial da República Federativa do Brasil. Brasília: 1991

BRASIL. Decreto no 4.073, de 3 de janeiro de 2002. Regulamenta a Lei no 8.159, de 8 de janeiro de 1991, que dispõe sobre a política nacional de arquivos públicos e privados. Diário Oficial da República Federativa do Brasil. Brasília: 2002.

BROOKS, Philip Coolidge. The Selection of Records for Preservation. American Archivist, Chicago, v. 3, n. 4, p. 221-234, October 1940.

CONSELHO INTERNACIONAL DE ARQUIVOS. Multilingual Archival Terminology. Disponível em: http://www.ica.org/14282/multilingual-archival-terminology/multilingual-archivalterminology.html. Acesso em 31/01/2014.

CONSELHO NACIONAL DE ARQUIVO. Resolução no 2, de 18 de outubro de 1995. Dispõe sobre as medidas a serem observadas na transferência ou no recolhimento de acervos documentais RICI: R.Ibero-amer. Ci. Inf., ISSN 1983-5213, Brasília, v. 9, n. 1, p. 162-177, jan./jun.2016. 
para instituições arquivísticas públicas. Diário Oficial da República Federativa do Brasil. Brasília: 1995.

CONSELHO NACIONAL DE ARQUIVO. Resolução no 5, de 30 de setembro de 1996. Dispõe sobre a publicação de editais para a Eliminação de Documentos nos Diários Oficiais da União, Distrito Federal, Estados e Municípios. Diário Oficial da República Federativa do Brasil. Brasília: 1996.

CONSELHO NACIONAL DE ARQUIVO. Resolução n 6, de 15 de maio de 1997. Dispõe sobre diretrizes quanto à terceirização de serviços arquivísticos públicos. Diário Oficial da República Federativa do Brasil. Brasília: 1997.

CONSELHO NACIONAL DE ARQUIVO. Resolução № 7, de 20 de maio de 1997. Dispõe sobre os procedimentos para a eliminação de documentos no âmbito dos órgãos e entidades integrantes do Poder Público. Diário Oficial da República Federativa do Brasil. Brasília: 1997.

CONSELHO NACIONAL DE ARQUIVO. Resolução no 14, de 24 de outubro de 2001. Aprova a versão revisada e ampliada da Resolução no4, de 28 de março de 1996, que dispõe sobre o Código de Classificação de Documentos de Arquivo para a Administração Pública: atividadesmeio a serem adotadas como modelo para os arquivos correntes dos órgãos e entidades integrantes do Sistema Nacional de Arquivos (SINAR), e os prazos de guarda e destinação de documentos estabelecidos na Tabela Básica de Temporalidade e Destinação de Documentos de Arquivo Relativos às Atividades-Meio da Administração Pública. Diário Oficial da República Federativa do Brasil. Brasília: 2001.

CONSELHO NACIONAL DE ARQUIVO. Resolução no 20, de 16 de julho de 2004. Dispõe sobre a inserção dos documentos digitais em programas de gestão arquivística de documentos dos órgãos e entidades integrantes do Sistema Nacional de Arquivos. Diário Oficial da República Federativa do Brasil. Brasília: 2004.

CONSELHO NACIONAL DE ARQUIVO. Resolução no 24, de 3 de agosto de 2006. Estabelece diretrizes para a transferência e recolhimento de documentos arquivísticos digitais para instituições arquivísticas públicas. Diário Oficial da República Federativa do Brasil. Brasília: 2006.

CONSELHO NACIONAL DE ARQUIVO. Resolução no 25, de 27de abril de 2007. Dispõe sobre a adoção do Modelo de Requisitos para Sistemas Informatizados de Gestão Arquivística de Documentos e-ARQ Brasil, pelos órgãos e entidades integrantes do Sistema Nacional de Arquivos. Diário Oficial da República Federativa do Brasil. Brasília: 2007.

CONSELHO NACIONAL DE ARQUIVO. Resolução no 36, de 19 de dezembro de 2012. Dispõe sobre a adoção das Diretrizes para a Gestão arquivística do Correio Eletrônico Corporativo pelos órgãos e entidades integrantes do Sistema Nacional de Arquivos - SINAR. Diário Oficial da República Federativa do Brasil. Brasilia: 2012. 
COOK, T. Interacción entre la teoria y la práctica archivistica desde La publicación del manual holandês en 1898. In: CONGRESSO INTERNACIONAL DE ARQUIVOS, 13, Pequim, 1996. Proceedings. Pequim, 1996.

COOK, T. Macroappraisal in Theory and Practice: Origens, Characteristics, and Implementation in Canada, 1950 - 2000. Archival Science, v. 2-4, n. 5, p.101-161, 2005.

COUTURE, C. La función valoración em La archivistica contemporânea: una sinergia entre varias consideraciones complementarias. Tabula, n. 6, p. 23-49, 2003.

EASTWOOD, Terry. La valoración archivística em las sociedades democráticas. In: COLÓQUIO INTERNACIONAL DE CIÊNCIA DE DOCUMENTACIÓN. CONGRESO DE ARCHIVE DE CASTILLA Y LEON, 2002. Departamento de Blioteconomie y e Documentación. Universidad de Salamanca, España, 2002.

JARDIM, J. M. A invenção da memória nos arquivos públicos. Ciência da Informação, Brasília, v. 25, n .2, p. 1-13,1995.

JENKINSON, H.A. Manual of Archive Administration. $2^{\text {nd }}$ ed. London: Percy Lund, Humphries, 1992.

KOLSRUD, O. The evolution of basic appraisal principles: some comparative observations.

American Archivist, v. 55, n. 1, p. 26-28, Winter 1992.

RIBEIRO, F.; SILVA, A. M. A avaliação de informação: uma operação metodológica. Páginas A\&B, n. 14, p. 7-37, 2004.

ROUSSEAU, J.Y.; COUTURE, C. Os fundamentos da disciplina arquivística. Lisboa: Publicações Dom Quixote, 1998.

SANTOS, V.B. Gestão de Documentos Eletrônicos: uma visão arquivística. 2a ed. Brasília: Abarq, 2005.

SCHELLENBERG, Theodore. Arquivos modernos: princípios e técnicas. Tradução de Nilza Teixeira Soares. 2a ed. Rio de Janeiro: FGV, 2002.

Recebido/Recibido/Received: 2015-08-31

Aceitado/Aceptado/Accepted: 2015-10-22 